\title{
The Effect of Cost Sharing on an Employee Weight Loss Program: A Randomized Trial
}

\section{Citation}

John, Leslie K., Andrea Troxel, William Yancy, Joelle Y. Friedman, Jingsan Zhu, Lin Yang, Robert Galvin, Karen Miller-Kovach, Scott Halpern, George Loewenstein, and Kevin Volpp. "The Effect of Cost Sharing on an Employee Weight Loss Program: A Randomized Trial." American Journal of Health Promotion 32, no. 1 (January 2018): 170-176.

\section{Published Version}

https://doi.org/10.1177/0890117116671282

\section{Permanent link}

http://nrs.harvard.edu/urn-3:HUL.InstRepos:41845076

\section{Terms of Use}

This article was downloaded from Harvard University's DASH repository, and is made available under the terms and conditions applicable to Open Access Policy Articles, as set forth at http:// nrs. harvard.edu/urn-3:HUL.InstRepos:dash.current.terms-of-use\#OAP

\section{Share Your Story}

The Harvard community has made this article openly available.

Please share how this access benefits you. Submit a story.

\section{Accessibility}


The Effect of Cost Sharing on an Employee Weight Loss Program:

A Randomized Trial

Leslie K. John, $\mathrm{PhD}^{1}$

Andrea B. Troxel, $\mathrm{ScD}^{2,3}$

William S. Yancy, Jr., MD ${ }^{4}$

Joelle Friedman, $\mathrm{MPA}^{3}$

Jingsan Zhu, MBA ${ }^{3}$

Lin Yang ${ }^{3}$

Robert Galvin, MD, MBA ${ }^{5}$

Karen Miller-Kovach, MBA, MS, RD

Scott D. Halpern, MD, $\mathrm{PhD}^{3,7}$

George Loewenstein, $\mathrm{PhD}^{3,8}$

Kevin Volpp, MD, $\mathrm{PhD}^{3,6,7,9}$

Author Affiliations:

1 Negotiations, Organizations and Negotiations Unit, Harvard Business School

2 Department of Biostatistics and Epidemiology, University of Pennsylvania

3 Center for Health Incentives, Leonard Davis Institute of Health Economics

4 Department of Medicine, Duke University School of Medicine

5 The Blackstone Group

6 Department of Medicine, University of Pennsylvania School of Medicine

7 Philadelphia Veterans Affairs Medical Center

8 Department of Social and Decision Sciences, Carnegie Mellon University

9 Department of Health Care Management, the Wharton School

Acknowledgments:

This study was funded by Weight Watchers. Weight Watchers assisted with the design and conduct of the study, the collection of the data, and reviewed the manuscript. Management, analysis, and interpretation of the data; preparation and approval of the manuscript; and decision to submit the manuscript for publication were all controlled by the authors. Dr. Volpp has received consulting income from CVS Caremark and VAL Health (where he is a Principal) and research funding from Horizon Blue Cross Blue Shield, Weight Watchers, Humana, Discovery (South Africa), and Merck. Dr. Troxel serves on the Scientific Advisory Board of VAL Health. Dr. Galvin is an employee of the Blackstone Group. No other potential conflicts have been identified. 


\begin{abstract}
Purpose: We tested the effects of employer subsidies on employee enrollment, attendance, and weight loss in a nationally-available weight management program.

Design: A randomized trial tested the impact of employer subsidy: 100\%; $80 \% 50 \%$ and a hybrid 50\% subsidy that could become a 100\% subsidy by attaining attendance targets. Trial registration: NCT01756066.
\end{abstract}

Setting and Subjects: 23,023 employees of two U.S. companies.

Measures: The primary outcome was the percentage of employees who enrolled in the weight management program. We also tested whether the subsidies were associated with differential attendance and weight loss over 12 months, as might be predicted by the expectation that they attract employees with differing degrees of motivation.

Analysis and Results: Enrollment differed significantly by subsidy level $(p<.0001)$. The $100 \%$ subsidy produced the highest enrollment (7.7\%), significantly higher than each of the lower subsidies (vs. $80 \%$ subsidy: 6.2\%, $p=.002$; vs. 50\% subsidy: $3.9 \%, p<.0001$; vs. hybrid: 3.7\%, $p<.0001)$. Enrollment in the $80 \%$ subsidy group was significantly higher than both lower subsidy groups (vs. 50\% subsidy: 3.9\%, $p<.0001$; vs. hybrid: 3.7\%, $p<.0001$ ). Among enrollees, there were no differences among the four groups in attendance or weight loss.

Conclusion: This pragmatic trial, conducted in a real-world workplace setting, suggests that higher rates of employer subsidization help individuals to enroll in weight loss programs, without a decrement in program effectiveness. Future research could explore the cost effectiveness of such subsidies or alternative designs. 
Key Words: Affordable Care Act, Cost Sharing \& Subsidies, Weight Loss, Weight Management, Obesity, Incentives, Behavioral Economics

Indexing Key Words: Manuscript format: research; Research purpose: intervention testing; Study design: randomized trial; Outcome measure: behavioral; Setting: workplace; Health focus: weight control; Strategy: incentives; Target population age: adults; Target population circumstances: geographic location, education/income level, race/ethnicity 
More than one-third of U.S. adults are obese (1) and the annual medical cost of caring for these individuals is estimated to be $\$ 147$ billion. Despite the prevalence of obesity, participation in weight loss programs is low in employer settings (2). Financial incentives have shown promise in increasing weight loss (3-10) and approximately 85\% of large employers used financial incentives for health behavior in 2014 (11). Under the Patient Protection and Affordable Care Act (PPACA), cost sharing will be allowed for some (though not all) preventive services, and the use of incentives to improve health outcomes is being more strongly encouraged (12). The impact of subsidizing health promotion programs on both participation and outcomes is an important unresolved question.

Reducing the price of cost-effective treatments or preventive services, such as weight management programs, could encourage enrollment and increase use of such services. However, it is possible that reducing cost (by offering the program at subsidized rates) may simply attract employees who are less committed to losing weight (i.e., a screening effect, (13-15), or cause patients to devalue the treatment (consistent with sunk cost effects, $(16,17)$, both of which would result in higher attrition rates and a less successful program overall. Expenditures to recruit more participants might not be an efficient use of resources in such cases. On the other hand, if subsidization helps people to overcome the inertia they face in beginning a weight loss program, one might expect subsidies to boost enrollment without reducing program effectiveness.

To determine the impact of varying levels of employer subsidy on employee enrollment in an effective nationally-available weight management program $(18)(19,20)$, as well as on attendance and weight loss, we conducted a randomized trial among 23,023 employees of two large U.S. companies. Participants were randomized to receive a 100\% subsidy, an $80 \%$ subsidy, a $50 \%$ subsidy, or a hybrid 50\% subsidy that could become a $100 \%$ subsidy based on 
participants’ meeting attendance targets $(21,22)$. Our primary outcome measure was enrollment rate, with secondary outcomes of attrition rates and weight loss at 12 months.

\section{METHODS}

Sample

The flow of participants through enrollment, intervention, and follow-up is shown in Figure 1. Enrollment was done on a rolling basis from January 2013 until July 2013. The intervention period was 12 months and data collection finished in July 2014. Participants meeting initial eligibility requirements were recruited using mailings. Eligible participants were benefits-eligible employees at two large employers within the United States. Employees had to be at least 18 years of age, have a body mass index $(\mathrm{BMI}) \geq 21 \mathrm{~kg} / \mathrm{m}^{2}$ (this is standard enrollment criteria for Weight Watchers, which we retained out of concern for external validity), and been hired prior to January 1, 2013.

Design and Intervention

Participants were randomized into one of the four intervention arms (1:1:1:1). Randomization was stratified by company and worksite (11 worksites at Company A and 31 worksites at Company B) and used variable block sizes of 4, 8, and 12 . The randomization assignments and study identification numbers were merged by on-site human resources personnel with employee lists at each location, after which participants were informed of their offer. Study investigators were blinded to individual intervention assignments until the analytic dataset was finalized at the completion of the trial. Program leaders were blinded to the randomization assignment; however, due to the nature of the intervention, participants could not be blinded to their subsidy level. 
The study was approved by the institutional review board of the University of Pennsylvania, which granted a waiver of consent.

Eligible employees ( $\mathrm{N}=23,023)$ were offered 12 months of a behavioral counseling program consisting of weekly group meetings (Weight Watchers) at one of four subsidized rates. Each employee received an offer letter at his/her home address that communicated the subsidy to which he/she was allocated. In addition, the standard Weight Watchers at Work marketing campaign was implemented; this included posters around the worksite and information sessions highlighting the potential to receive at least $50 \%$ off the cost of the Weight Watchers monthly pass program (the monthly pass program provides subscribers with access to weekly Weight Watchers meetings and e-tools that promote self-monitoring), and the time-limited nature of the offer. Employees were given a personalized ID number and password and directed to the Weight Watchers website to enroll in the program. Baseline weight measurements were obtained at the first meeting that was attended. After the 12-month subsidy period, employees had the option of continuing with the full-priced program.

The regular price of the program, as offered through employers, was \$34.35 per month, payable by credit card at the end of the month. We tested the impact of the following employer subsidies on program enrollment: 100\% (program is free to employee), 80\% (employee pays $20 \%$ of price), $50 \%$ (employee pays $50 \%$ of price), or a hybrid subsidy. In the hybrid subsidy arm, participants received a guaranteed 50\% subsidy, which was increased to $100 \%$ contingent on attendance. Specifically, participants in this arm received a 100\% subsidy for months in which they attended at least three meetings. These participants were charged the $50 \%$ price 
upfront, which was subsequently reimbursed at the end of each month in which the attendance goal had been met.

Enrollees were instructed to attend a group weight loss meeting every week and could do so at work and/or in their communities. Participants were weighed at each meeting and attendance was recorded per standard Weight Watchers procedures; a centralized system recorded enrollees’ weight measurements and attendance rates, which served as our secondary dependent measures. We also received data on all use of Weight Watchers' online $e$-tools (a suite of digital applications, including a food tracker) by study participants. In addition, at the end of the 12-month program, enrollees were offered a $\$ 20$ bonus for providing a final weigh-in at a Weight Watchers location.

Analysis

Our primary outcome was the percentage of employees who enrolled in the program, assessed using chi-square tests. We hypothesized that enrollment would increase as the subsidy increased. We also assessed program attendance and weight loss among enrollees, using generalized linear models. We adopted a per-protocol approach, evaluating each enrollee according to his/her randomized offer, regardless of degree of participation. The per-protocol approach enabled us to test for a possible perverse effect of the subsidies - that employees who are motivated by higher subsidies to join health promotion programs could be less committed to losing weight; therefore, higher subsidy arms might be associated with less weight loss.

Some enrollees failed to provide a monthly weight; we multiply imputed missing weight measurements based on the following variables: arm indicator (blinded), enrollment calendar month, cancellation within 12 months (y/n), age, gender, baseline height, total food tracking days, total exercise tracking days, week of most recent weigh-in, weight at most recent weigh-in, 
interaction between week of most recent weigh-in and weight at most recent weigh-in, and number of total weigh-ins since enrollment. We assessed the robustness of our results by using different imputation approaches (baseline observation carried forward, which assumes participants lost no weight; and last observation carried forward, which assumes participants had no change in weight beyond what was measured). We controlled for baseline weight since it differed between arms among enrollees. We report weight loss in pounds because all communication with study participants about weight loss was in pounds (the study population was more familiar with pounds than kilograms).

Our power calculations were aimed at detecting a difference in participation rates between arms of approximately 1.5 percentage points. A sample size of 20,000, evenly randomized to the four arms, provided more than $80 \%$ power to detect this difference. All tests were 2-sided; pairwise tests between arms used a significance level of 0.017 to adjust for multiple comparisons when comparing the intervention arms to the $50 \%$ subsidy arm. We used SPSS v15.0 (SPSS Inc., Chicago, Illinois) and SAS 9.3 (SAS institute Inc., Cary, NC) to analyze the data.

\section{RESULTS}

The sample was predominantly female (90\%); mean age was 48 years, mean baseline weight was 200.5 pounds, mean BMI was $33.3 \mathrm{~kg} / \mathrm{m}^{2}$ (Table 1), and 92\% of the sample had unhealthy BMIs (i.e., BMIs of at least 25).

Enrollment rates were significantly different based on the level of the subsidy offered $(p<.0001$; Figure 2$)$. The $100 \%$ subsidy produced the highest enrollment rate (7.7\%), which was significantly higher than each of the lower subsidy groups (vs. $80 \%$ subsidy: $6.2 \%, p=.002$; vs. 
50\% subsidy: 3.9\%, $p<.0001$; vs. hybrid subsidy: 3.7\%, $p<.0001)$. The $80 \%$ subsidy enrollment rate of $6.2 \%$ was significantly higher than both of the lower subsidy groups (vs. $50 \%$ subsidy: 3.9\%, $p<.0001$; vs. hybrid subsidy: 3.7\%, $p<.0001)$. The enrollment rates among participants in the $50 \%$ and the hybrid subsidy arms were not significantly different $(p=.70)$. Interestingly, enrollees in the high subsidy arms (i.e. $80 \%$ subsidy and 100\% subsidy) had, on average, lower baseline BMIs relative to those in the low subsidy arms (Table 1).

Meeting attendance decreased steadily over time and declined at similar rates across arms (Figure 3). About $60 \%$ of participants across arms weighed in by the end of one month, about $20 \%$ by the end of six months, and about $10 \%$ by the end of 12 months. While members on average attended about two meetings per month in the first few months, by month five this dropped to an average of about one meeting per month. We found no differences in $e$-tool utilization by arm ( $p=.95)$, with rates of utilization of about $60 \%$ per month initially dropping to about 20\% by month 6 and 10\% by month 12 .

Mean weight loss was also similar across arms at 12 months $(p=.28)$, with a mean weight loss of 2.6 pounds (95\% CI 5.7 lb loss - $0.3 \mathrm{lb}$ gain) in the $100 \%$ subsidy arm; 1.5 pounds (95\% CI $5.6 \mathrm{lb}$ loss $-1.3 \mathrm{lb}$ gain) in the $80 \%$ subsidy arm; 3.8 pounds (95\% CI $7.9 \mathrm{lb}$ loss $-0.4 \mathrm{lb}$ gain) in the $50 \%$ subsidy arm, and 4.0 pounds (95\% CI $8.1 \mathrm{lb}$ loss $-0.1 \mathrm{lb}$ gain) in the hybrid subsidy arm. Overall, participants weighed significantly less on average at the end of the 12 month program than they did upon enrollment (average weight loss $=2.7$ pounds, $p<.0001$ versus 0 pounds). The percentage of participants who had lost at least $5 \%$ of body weight peaked around month 4 at about 30\% and was highest in the hybrid arm though by 12 months this was similar across arms and was about $10 \%$ in all arms. 


\section{DISCUSSION}

Previous research has found that inertia is a significant barrier to engaging in selfbeneficial behaviors such as exercise and weight loss $(23,24)$. Our pragmatic trial, conducted using standard Weight Watchers recruitment materials, enrollment and implementation procedures for the worksite, suggests that higher rates of employer subsidization are an effective way to increase enrollment in a weight management program, helping people to initiate positive change (i.e., weight loss). Program enrollment rates increased with the degree of subsidy such that a $100 \%$ subsidy doubled the rate of enrollment compared to a $50 \%$ subsidy. Although the higher subsidies attracted individuals with lower BMIs, and hence, possibly reduced motivation to lose weight relative to the average person in the lower subsidy arms, program effectiveness was inconsistent with such a screening effect: weight loss at 12 months and program attendance did not differ significantly by subsidy level. This pattern of findings suggests that the subsidies served to help people to overcome the inertia the face in beginning a weight loss program.

These findings have broader implications for employer subsidization of participation in health improvement programs, suggesting that higher degrees of subsidization are effective at increasing enrollment and may not result in lower rates of performance within the program among enrollees. Employers and health plans often struggle with low rates of enrollment and ongoing participation in health-improvement programs; they may want to consider subsidization as a path to increasing enrollment. Employers often subsidize gym membership, health insurance, and other activities partly as a way of increasing the attractiveness of working at a particular firm and partly to encourage certain types of activity.

Surprisingly, the 50\% subsidy and the hybrid subsidy - in which enrollees were guaranteed a 50\% subsidy, but could earn a 100\% subsidy contingent on attendance - produced 
equivalent enrollment rates. Beyond simple misunderstanding (i.e., failing to realize that one is eligible for an extra 50\% discount contingent on attendance), the behavioral economics literature suggests a couple of possible explanations for this equivalence, the first having to do with (un)awareness of bias. It is possible that people are naïve, in the sense that in prospect, they have difficulty appreciating how challenging it will be for them to lose weight (25). This would cause a person to underappreciate, and hence fail to be motivated by, the hybrid incentive system.

The psychology of value also provides clues to explain the observed equivalence between the $50 \%$ subsidy and the hybrid subsidy arms (26). Participants in our hybrid arm paid the (halfprice) rate upfront and subsequently were reimbursed if they attained the participation goal, bringing them up to the $100 \%$ subsidy. If they failed to attain the goal, they simply forewent the reimbursement (i.e., gain). An alternative potentially more effective approach would have been to only charge these participants on the back-end, if they failed to attain the goal, in which case failure is a loss, as participants must pay the (half-price) monthly fee. On the one hand, the latter could backfire: fining employees for failures could cause serious backlash (and in fact, this is the primary reason why we opted against this approach). Future research coulldcompare the effectiveness of these approaches.

In our study, discounts were framed as such - employees were aware that they were being offered the weight loss program at a subsidized rate. In the Affordable Care Act preventive services are instead framed as free - offered "at no cost to you.” (27) Future research might test the framing of cost sharing programs; framing them as subsidized might make them seem like a deal, which could increase usage rates. By contrast, people may devalue services that are framed as free (28). 
Although the relative difference in enrollment as a function of the incentive subsidy was large (uptake in the $100 \%$ subsidy arm was double that of the $50 \%$ subsidy arm), in absolute terms, it was fairly modest: $7.7 \%$ of those offered a free weight loss program choose to enroll. It is possible that enrollment rates were restricted by our inability to broadly market the subsidies. Since employees at the same firm were randomized to different subsidies, we could only privately inform employees of their subsidy offer (broadly and publically marketing the different subsidies across the firm would have seriously undermined internal validity). If the $100 \%$ subsidy were used universally, it would be possible to market it aggressively. Thus, our observed enrollment rates likely represent a conservative estimate of the incremental effect of higher subsidies on enrollment. In addition, we did not have access to email addresses; this type of communication might have further helped to increase awareness of the program and allowed for further accentuation of the differences between programs.

Randomizing employees within the same firm to the different treatments is advantageous from an experimental design perspective, for it enabled us to keep possible firm effects constant. A downside of this design choice is that it raises the possibility for contamination: it is possible that employees discussed their (differing) subsidy levels with each other. However, the benefit of within-firm randomization offsets this downside; moreover, to the extent that contamination occurred, we think it likely to have only made it more difficult for us to detect effects of the intervention. A further limitation is that attrition rates were high, limiting our ability to conduct robust imputation of missing data, as well as our ability to detect small differences in weight loss at 6- and 12- month follow-ups.

In this pragmatic, real-world experiment we observed that employer subsidies increased enrollment in a nationally-available weight management program without adversely affecting 
program participation or weight loss. Subsequent research should assess the cost effectiveness of such subsidies, and could test alternative ways of increasing enrollment, reducing attrition, and boosting weight loss once subsidies have been applied to get employees into the program.

\section{SO WHAT?}

What is already known on this topic?

More than one-third of U.S. adults are obese; the annual medical cost of caring for them is $\$ 147$ billion. Previous research has found inertia to be a significant barrier to engaging in selfbeneficial behaviors such as exercise and weight loss.

IWhat does this article add?

Despite the prevalence and costs of obesity, participation in weight loss programs is low in employer settings. In this paper, we addressed the important and previously unresolved question of the degree to which subsidization of such programs by employers affects enrollment, participation, and success rates in such programs.

What are the implications for health promotion practice or research?

This pragmatic trial, conducted in a real-world workplace setting, suggests that higher rates of employer subsidization can help individuals to overcome the inertia they face in beginning a weight loss program. Large subsidies produced enrollment increases that were large relative to lower subsidies, though modest in absolute terms. The increased enrollment did not seem to come at the expense of program outcomes: attendance and weight loss did not differ 
Cost Sharing in an Employee Weight Loss Program 14

significantly by employer subsidy level. Future research could explore the cost effectiveness of such subsidies. 
Cost Sharing in an Employee Weight Loss Program 15

\section{REFERENCES}

1 Ogden CL, Carroll MD, Kit BK, Flegal KM. PRevalence of childhood and adult obesity in the united states, 2011-2012. JAMA. 2014;311(8):806-14.

2 Towers W. Performance in an era of uncertainty. New York, NY; 2012.

3 Jeffery RW, Thompson PD, Wing RR. Effects on weight reduction of strong monetary contracts for calorie restriction or weight loss. Behaviour Research and Therapy. 1978;16(5):363-9.

4 Jeffery RW, Gerber WM, Rosenthal BS, Lindquist RA. Monetary contracts in weight control: effectiveness of group and individual contracts of varying size. Journal of Consulting and Clinical Psychology. 1983;51(2):242-8.

5 Mann RA. The behavior-therapeutic use of contingency contracting to control an adult behavior problem: weight control. Journal of Applied Behavior Analysis. 1972;5(2):99-109. 6 Jeffery RW, Bjornson-Benson WM, Rosenthal BS, Kurth CL, Dunn MM. Effectiveness of monetary contracts with two repayment schedules on weight reduction in men and women from self-referred and population samples. Behavior Therapy. 1984;15(3):273-9.

7 Jeffery RW, Wing RR, Thorson C, et al. STRENGTHENING BEHAVIORAL INTERVENTIONS FOR WEIGHT-LOSS - A RANDOMIZED TRIAL OF FOOD PROVISION AND MONETARY INCENTIVES. Journal of Consulting and Clinical Psychology. 1993;61(6):1038-45.

8 John LK, Loewenstein G, Troxel AB, Norton L, Fassbender J, Volpp KG. Financial Incentives for Extended Weight Loss: A Randomized, Controlled Trial. Journal of General Internal Medicine. 2011;26(6):621-6.

9 Kullgren JT, Troxel AB, Loewenstein G, et al. Individual- versus group-based financial incentives for weight loss: a randomized, controlled trial. Annals of internal medicine. 2013;158(7):505-14.

10 Volpp K, John L, Troxel AB, Norton L, Fassbender J, Loewenstein G. Financial IncentiveBased Approaches for Weight Loss: A Randomized Trial. Journal of the American Medical Association. 2008;300(22):2631-7.

11 Towers W. Employer survey on purchasing value in health care; 2014.

12 Madison KM, Schmidt H, Volpp KG. Smoking, obesity, health insurance, and health incentives in the Affordable Care Act. Journal of the American Medical Association.

2013;310(2):143-4.

13 Roy AD. Some Thoughts on the Distribution of Earnings. Oxford Economic Papers. 1951;3(2):135-46.

14 Oster SM. Strategic Management for Nonprofit Organizations: Theory and Cases. New York: Oxford University Press; 1995.

15 Ashraf N, Berry J, Shapiro JM. Can Higher Prices Stimulate Product Use? Evidence from a Field Experiment in Zambia. American Economic Review. 2010;100(5):2383-413.

16 Arkes H, Blumer C. The Psychology of Sunk Cost. Organizational Behavior and Human Decision Processes. 1985;35(1):304-9.

17 Thaler R. Toward a Positive Theory of Consumer Choice. Journal of Economic Behavior \& Organization. 1980;1(1):39-60.

18 Jebb SA, Ahern AL, Olson A, et al. Primary care referral to a commercial provider for weight loss treatment versus standard care: a randomised controlled trial. The Lancet.

2011;378(9801):1485-92. 
19 Heshka S, Anderson J, Atkinson R, al. e. Weight loss with self-help compared with a structured commercial program: A randomized trial. Journal of the American Medical Association. 2003;2003(289):14.

20 Johnston CA, Rost S, Miller-Kovach K, Moreno JP, Foreyt JP. A Randomized Controlled Trial of a Community-based Behavioral Counselling Program. The Journal of American Medicine. 2013;126(12):19-24.

21 Pinto AM, Fava JL, Hoffman DA, Wing RR. Combining behavioral weight loss treatment and a commercial program: A randomized clinical trial. Obesity. 2013;21(4):673-80.

22 Gudzune KA, Doshi RS, Mehta AK, et al. Efficacy of Commercial Weight-Loss Programs: An Updated Systematic Review. Annals of internal medicine. 2015;162(7):501-12.

23 Madrian BC, Shea DF. The Power of Suggestion: Inertia in 401(k) Participation and Savings Behavior. The Quarterly Journal of Economics. 2001 November 1, 2001;116(4):1149-87.

24 O'Donoghue T, Rabin M. Choice and Procrastination. The Quarterly Journal of Economics. 2001;116(1):121-60.

25 O'Donoghue T, Rabin M. Doing it now or later. The American Economic Review. 1999;89(1):103-24.

26 Kahneman D, Tversky A. Prospect theory: An analysis of decision making under risk. Econometrica. 1979;47:263-91.

27 HealthCare.gov. [cited; Available from: https://www.healthcare.gov/preventive-carebenefits/

28 Shampanier K, Mazar N, Ariely D. Zero as a special price: the true value of free products. Marketing Science. 2007;26(6):742-57. 
Table 1: Baseline characteristics of enrollees.

\begin{tabular}{|c|c|c|c|c|c|c|}
\hline & $\begin{array}{c}50 \% \\
\text { subsidy } \\
(n=223)\end{array}$ & $\begin{array}{l}50 / 100 \% \\
\text { subsidy } \\
(n=215)\end{array}$ & $\begin{array}{c}80 \% \\
\text { subsidy } \\
(n=358)\end{array}$ & $\begin{array}{c}100 \% \\
\text { subsidy } \\
(n=444)\end{array}$ & $\begin{array}{c}\text { Entire } \\
\text { sample } \\
\text { (n=1240) }\end{array}$ & $\begin{array}{l}p- \\
\text { value* }\end{array}$ \\
\hline$\%$ from Site 1 & 65 & 63 & 65 & 63 & 64 & $N / A$ \\
\hline$\%$ Female & 91 & 89 & 91 & 89 & 90 & NS \\
\hline $\begin{array}{l}\text { Mean age, years } \\
\text { (SD) }\end{array}$ & $\begin{array}{r}49.0 \\
(10.2)\end{array}$ & $\begin{array}{r}48.3 \\
(10.0)\end{array}$ & $\begin{array}{r}46.9 \\
(11.1)\end{array}$ & $\begin{array}{r}47.7 \\
(10.4)\end{array}$ & $\begin{array}{r}47.8 \\
(10.5)\end{array}$ & NS \\
\hline $\begin{array}{l}\text { Mean baseline } \\
\text { weight, Ibs (SD) }\end{array}$ & $\begin{array}{l}205.2 \\
(49.2)\end{array}$ & $\begin{array}{l}205.8 \\
(48.8)\end{array}$ & $\begin{array}{l}198.9 \\
(48.6)\end{array}$ & $\begin{array}{l}197.3 \\
(42.9)\end{array}$ & $\begin{array}{l}200.6 \\
(46.9)\end{array}$ & 0.06 \\
\hline $\begin{array}{l}\text { Mean BMI, kg/m² } \\
\text { (SD) }\end{array}$ & $\begin{array}{l}34.1 \\
(7.1)\end{array}$ & $\begin{array}{l}34.1 \\
(7.1)\end{array}$ & $\begin{array}{l}33.3 \\
(7.4)\end{array}$ & $\begin{array}{l}32.5 \\
(6.7)\end{array}$ & $\begin{array}{l}33.3 \\
(7.1)\end{array}$ & 0.01 \\
\hline
\end{tabular}

${ }^{*} p$-values are from $\mathrm{F}$ test for continuous variables and chi-square test for categorical variables. 


\section{FIGURE CAPTIONS}

Figure 1: Consort diagram

Figure 2: Enrollment rates were highest in the $100 \%$ subsidy arm.

Figure 3: Attendance rates drop steadily but at similar rates by arm ( $p=.81)$. 


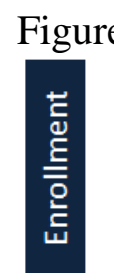

Figure 1

틈
흔
든

Randomized to $50 \%$ subsidy

$(\mathrm{n}=5,755)$

Enrolled in program

$(n=223)$

Lost to follow up

$(n=36)$

Cancelled membership

$(n=128)$

(1)

Analyzed $(n=223)$

Randomized ( $n=23,023$ )

Excluded $(n=0)$

Lost to follow up

$(\mathrm{n}=25)$

Cancelled membership ( $n=145$ )

Randomized to hybrid (50-100\%) subsidy

$(\mathrm{n}=5,756)$

Enrolled in program $(n=215)$

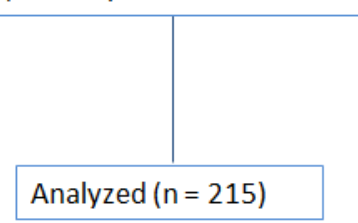

Randomized to $80 \%$ subsidy

( $n=5,756$ )

Enrolled in program

( $n=358$ )

Lost to follow up

( $n=78$ )

Cancelled membership

( $n=221$ )

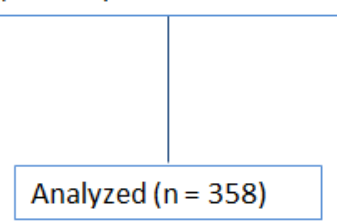

Randomized to $100 \%$

subsidy

( $\mathrm{n}=5,756$ )

Enrolled in program

( $n=444)$

Lost to follow up

( $\mathrm{n}=88$ )

Cancelled membership ( $n=253$ )

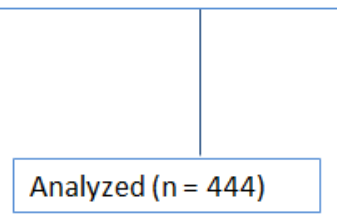

*Note: Lost to follow-up = Participant came to first meeting only 
Figure 2

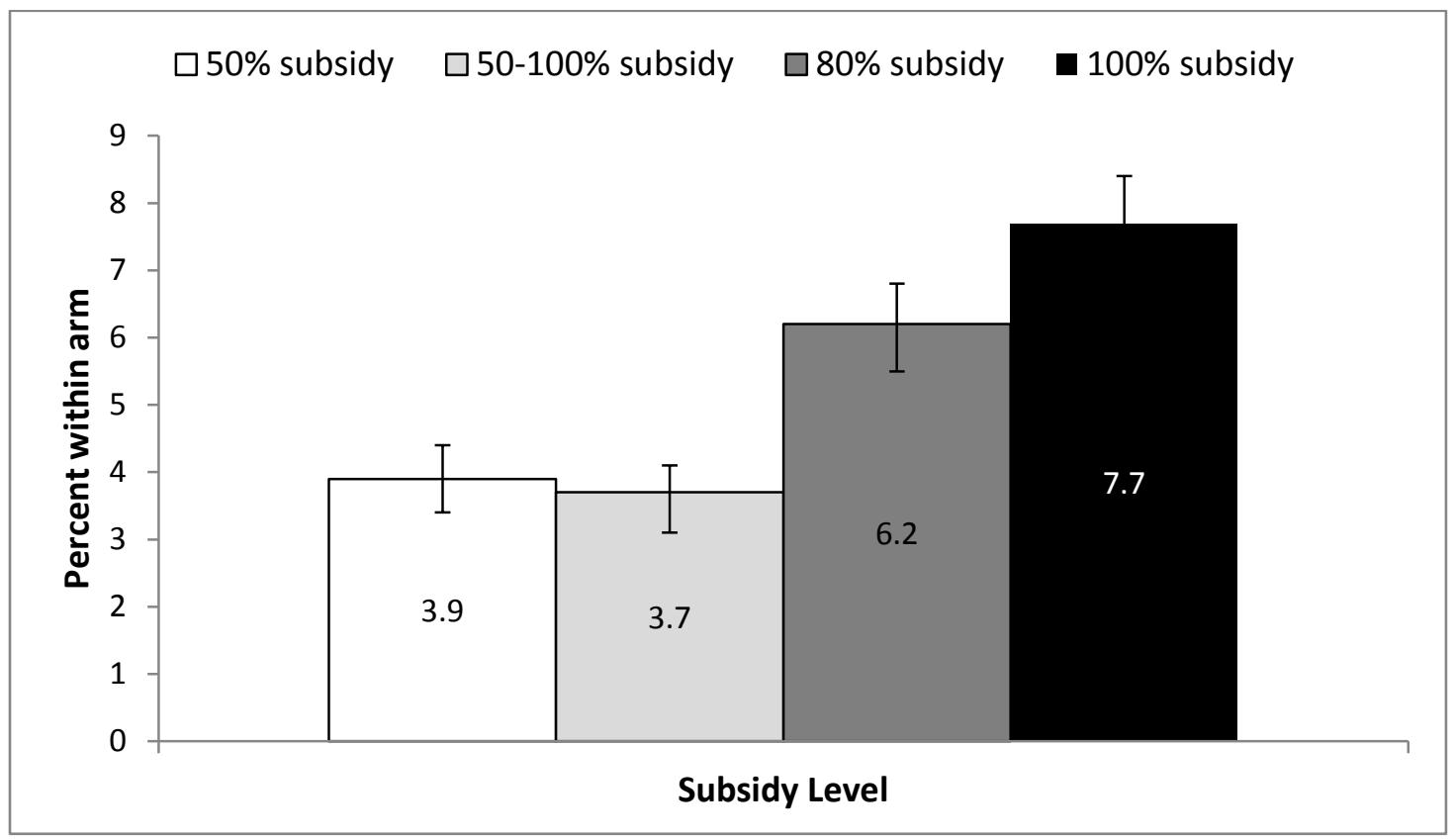


Cost Sharing in an Employee Weight Loss Program 21

Figure 3

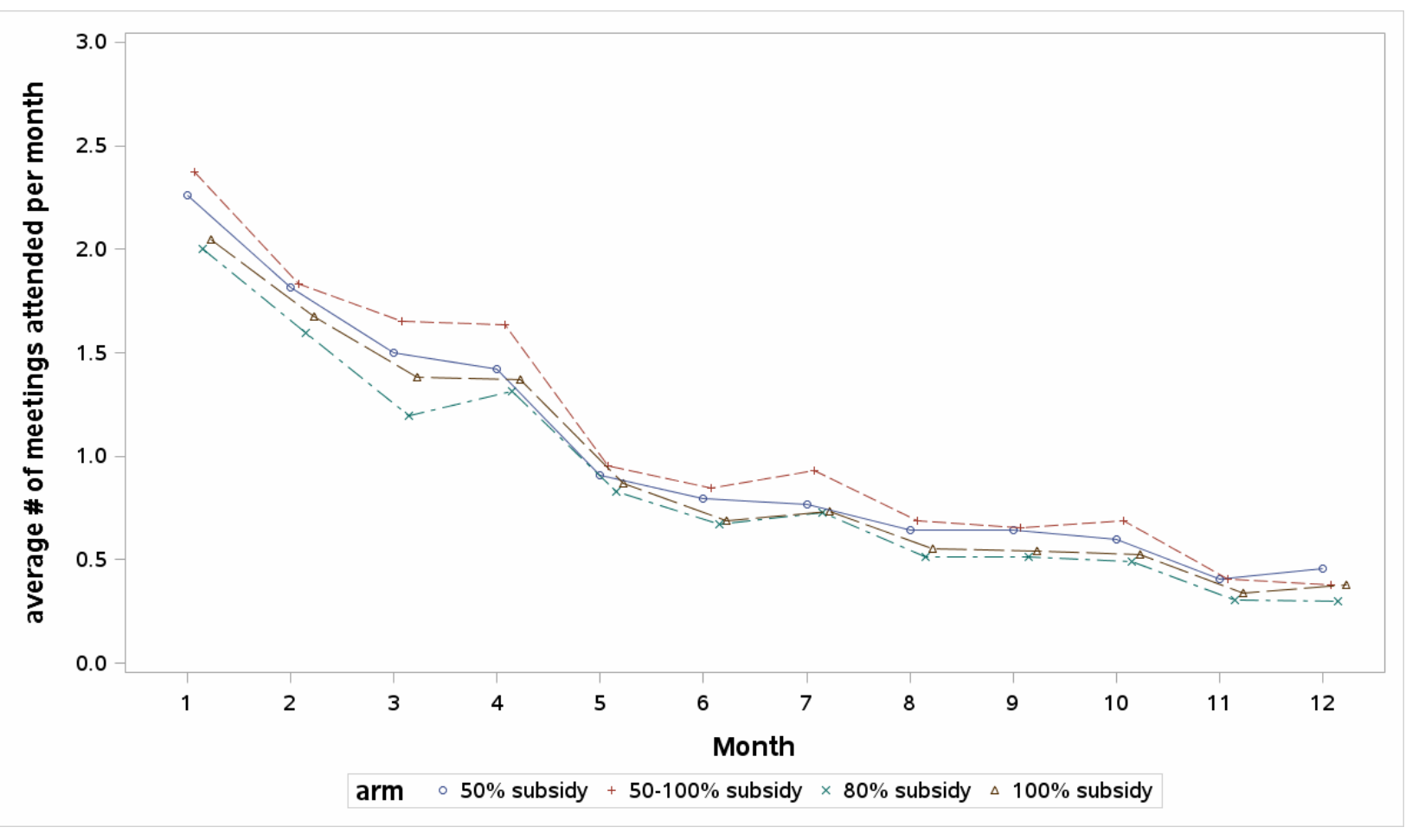

